\title{
What Can Science, Technology, and Innovation Offer in the Achievement of Sustainable Development Goals?
}

\author{
Ademola A. Adenle, Marian R. Chertow, Ellen H.M. Moors, \\ and David J. Pannell
}

\section{Introduction}

Since 2000, significant achievements in global development have taken place, as evidenced by the lifting of one billion people out of extreme poverty and in the reduction of chronic hunger in many regions of the developing world (Word Bank 2018). Concerted international efforts aimed at meeting the millennium development goals (MDGs) in the period 2000-2015 have drawn the attention of many governments in developing countries, and helped shift their public policy and decision-making priorities (UN 2015). Despite these important achievements, much more needs to be done to bring people out of poverty, to improve public health, and to respond to environmental problems.

To expand and build on MDGs' successes, the United Nations' (UN) 2030 agenda for sustainable development (UN 2015) has included the establishment of a set of sustainable development goals (SDGs). SDGs break new ground in that they incorporate additional dimensions of socioeconomic and environmental concerns into the development agenda, within the setting of novel indicators of success across various sectors. The new United Nations 2030 Agenda for Sustainable Development has primarily been designed to end poverty, protect the planet, and ensure prosperity for all and nurture peaceful, inclusive societies (UN 2015). Associated with the 17 SDGs (Table 1.1) are 169 targets and 304 proposed indicators that are cross-cutting and multidimensional in nature, designed primarily to monitor SDG progress and to provide accountability for the implementation of the SDGs.

New policies that recognize the benefits of science, technology, and innovation (STI) and their potential risks are needed to implement the SDG agenda successfully by 2030. Recognizing this need, the Technology Facilitation Mechanism (TFM) was agreed to among UN member states in 2015. To support the achievement of the SDGs, "the TFM will facilitate multi-stakeholder collaboration and partnerships through the sharing of information, experiences, best practices and policy advice among Member 
Table 1.1 The sustainable development goals

Goal 1. End poverty in all its forms everywhere

Goal 2. End hunger, achieve food security and improved nutrition, and promote sustainable agriculture

Goal 3. Ensure healthy lives and promote well-being for all at all ages

Goal 4. Ensure inclusive and equitable quality education and promote lifelong learning opportunities for all

Goal 5. Achieve gender equality and empower all women and girls

Goal 6. Ensure availability and sustainable management of water and sanitation for all

Goal 7. Ensure access to affordable, reliable, sustainable, and modern energy for all

Goal 8. Promote sustained, inclusive, and sustainable economic growth, full and productive employment, and decent work for all

Goal 9. Build resilient infrastructure, promote inclusive and sustainable industrialization, and foster innovation

Goal 10. Reduce inequality within and among countries

Goal 11. Make cities and human settlements inclusive, safe, resilient, and sustainable

Goal 12. Ensure sustainable consumption and production patterns

Goal 13. Take urgent action to combat climate change and its impacts

Goal 14. Conserve and sustainably use the oceans, seas, and marine resources for sustainable development

Goal 15. Protect, restore, and promote sustainable use of terrestrial ecosystems, sustainably manage forests, combat desertification, and halt and reverse land degradation and halt biodiversity loss

Goal 16. Promote peaceful and inclusive societies for sustainable development, provide access to justice for all, and build effective, accountable, and inclusive institutions at all levels

Goal 17. Strengthen the means of implementation and revitalize the Global Partnership for Sustainable Development

Source: United Nations (2015).

States, civil society, the private sector, the scientific community, United Nations entities and other stakeholders" (UN n.d.). The TFM includes three main elements: an interagency task team on STI for the SDGs, a multistakeholder forum on STI for the SDGs (occurring annually, starting in 2016), and an online platform that provides a gateway to information on STI initiatives, mechanisms, and programs (not yet operational, as of April 2020) (UN n.d.). The existence of the TFM, and the participation by numerous stakeholders, reflects a broad recognition of the essential role of STI in delivering SDGs, and of the potential for improving the capacity of many developing countries to undertake STI initiatives that will help them achieve SDGs.

STI applications can make multiple contributions to the achievement of SDGs. Developing countries in particular will need to harness STI, while managing resulting trade-offs, to deliver on the three pillars of sustainable development: environmental, social, and economic. The SDGs simultaneously touch upon all three aspects. 
Integrating these aspects into the implementation of the SDGs is a key challenge for both policymakers and researchers who need to address them in interdisciplinary research and innovation projects (Biermann et al. 2017). There is a range of barriers to channeling STI toward accomplishing the SDGs. Therefore, to meet its SDG targets, the global community must mobilize STI across multiple sectors, new investments in innovation, and policy design that addresses the barriers.

A lack of clear vision and understanding among national governments about how STI can contribute to achieving the SDGs remains a significant challenge. Our aim in this book is to address the gap by raising understanding of STI among domestic and international organizations concerned with sustainable development in light of the SDGs.

This book contains 26 chapters and involves 74 authors from 55 institutions across 19 countries around the world. The chapters are not all inclusive across STI. Rather we target three themes in which STIs are crucial for sustainable development: environment and energy, health, and agriculture. Within each theme the chapters offer thoughtful background on particular issues concerning SDGs. We address each issue with analysis of a concept or theory, a set of tools or practices, or policy-relevant advice based on data collected to find paths forward to sustainability transitions. In this way our work is part textbook, part handbook, and part idea/concept book. Some chapters address SDGs in specific geographies and others are topical without a specific geographic focus. While intending to serve the broadest STI and policymaker audience, on balance the book tilts toward developing countries and regions more than developed ones for examples.

\section{STI and Sustainable Development}

Advances in science and technology can help to deliver basic human needs, enhance economic productivity, reduce environmental impacts, and improve the quality of products and services (Holdren 2008). The United Nations and other international organizations have long recognized the importance of STI to modern societies and the way the emergence of technological innovation has shaped the world and contributed to economic development (UN 2002).

As part of the efforts to achieve sustainable development, linkages between STI and the earlier set of MDGs were highlighted, particularly in the contexts of promoting industrialization, increasing productivity, achieving food security, promoting access to quality health systems, and creating decent jobs. Yet a limited emphasis was placed on the role of STI in meeting MDG targets both at the national and international levels, inhibiting the achievement of the MDGs, especially in developing regions (UN 2014).

The integration of STI into a broader agenda for achieving sustainable development remains complex, especially at the international level. According to the United Nations, despite efforts by the UN Conference on Trade and Development to conduct 
national STI policy reviews, such reviews are not compulsory so universal coverage was not achieved (UN 2016).

The World Bank (2010) argued that there has been a lack of partnerships between developed and developing countries around STI, meaning that systematic knowledge transfer between the Global South and Global North was lacking, thereby undermining the role of STI in fostering sustainable development and economic growth in the Global South. There are a number of reasons why international cooperation for STI activities has been problematic. In developing countries, lack of investment, poor institutional conditions, weak governance, and limited infrastructure, among other things, have been blamed for slow advances in scientific and technological development (Knack and Keefer 1995; Word Bank 2010). A case study by Ramón and Gaudin (2014), for example, argues that Central American countries fail to implement national STI policies owing to deficient funds and weak infrastructure, for research and development (R\&D) and more generally. In addition, many developing countries lack the human capital, socioeconomic institutions, and technology systems to engage in international cooperation to advance STI's contributions to sustainable development (Adenle et al. 2015; Ramón and Gaudin 2014).

International regimes pertaining to intellectual property rights (IPR) are designed to protect the interests of (mostly developed-country) IP creators. While this has the advantage of incentivizing the creation of new IP that can be commercially exploited, it may not be the regime that would most effectively foster international cooperation to help drive sustainable economic growth in the developing world (Bozeman 2000; Roffe and Santa Cruz 2007). Nevertheless, some countries have tailored IPR to meet their specific needs by building national innovation systems that target human capital development, enterprise development, and STI policy development, all of which can contribute to economic transformation. Studies have shown that a number of countries have come out of poverty and built competitive economies through a growth trajectory aligned with strong STI capacities as underpinned by effective national innovation systems. For example, Chung (2002) argues that South Korea's industrialization is largely driven by STI policy that focuses on national R\&D investment; entrepreneurship development; partnerships between academia, public research institutes, and industries; and a well-educated workforce. This experience reinforces the importance of STI in helping to achieve national level SDGs.

The role of frugal innovation in addressing sustainable development issues has also become more important in recent discussion (Khan 2016; UNCTAD 2017). Frugal innovation concerns the (re)development of products, services, and systems at the lowest possible cost, while retaining functionality. Here, the critical question raised in the UNCTAD report is how to harness STI policy to develop low-cost technologies that can service marginalized groups facing resource constraints as they try to advance sustainable development, and ultimately contribute to the SDGs. Unlike the STI activities driven by market-based incentives for R\&D investments, frugal innovation is generally associated with untapped markets and very-low-income grassroots communities (Seyfang and Smith 2007). Yet STI policies to promote grassroots 
innovation for the achievement of SDGs are still largely absent at the global and national levels (Khan 2016; Levänen et al. 2016).

\section{STI and the Framework of the Sustainable Development Goals}

This book focuses on the 17 SDGs as guides and motivators to foster sustainable socioeconomic growth and improve quality of life around the world. Of 169 SDG targets, 48 targets are related to STI (GSDR 2016). Many of the remaining 121 targets also touch on STI, in that technological innovation has a role to play in reaching the targets. This underlines the critical role of STI in advancing economic performance and inclusive development, especially in light of the limited recognition of its contribution in the former MDG era (UN 2014). One could argue that weak coordination of STI at the global level contributed to the underperformance of STI in terms of its contributions toward the achievement of MDGs, especially in developing countries. Despite the 2004 Millennium Declaration promoting science and technology for MDGs (United Nations Economic and Social Council 2004), emphasizing the important role of human capital development and local capacity building to facilitate international technology transfer, the recognized role of new and emerging technologies as part of global STI activities was limited (see chapter 20).

We have structured this book around three science-based arenas in which it is clear that STI is important for achieving sustainable development: 1) environment and energy, 2) health, and 3) agriculture. While our themes tend to be studied by separate disciplines, we recognize that the SDG framework is cross-cutting, multidimensional, and interlinked (e.g., Biermann et al. 2017; Kanie et al. 2017). The framework covers some specific global thematic priorities, such as SDG2 (end hunger) or SDG5 (gender equality) and includes some with a broader scope, such as SDG11 (inclusive, safe cities) or SDG9 (sustainable industrialization).

As noted earlier, the lack of national STI policy frameworks has hampered the implementation of national sustainable development strategies. Such national policies can benefit from international frameworks providing guidance, especially the TFM (UN 2016). Through stakeholder participation in international forums and the sharing of knowledge and experiences related to STI initiatives, mechanisms, and programs, the TFM can make a substantial contribution to the delivery of SDGs. It is an important initiative, but only one element of many that will be needed if STI is to be fully effective in advancing SDGs.

Another initiative has been the clean development mechanism (CDM) created under the Kyoto Protocol by the UN Framework Convention on Climate Change (UNFCCC). To decrease greenhouse gas emissions, the CDM encouraged the transfer of low-carbon sustainable technologies. CDM technology transfer was relatively successful in China, Brazil, and India, and this was attributed to their strong 
technological capabilities (Dechezleprêtre et al. 2009), as well as to strong institutional support and high-quality infrastructure compared to other developing regions.

However, the CDM failed to achieve its aims in a number of developing regions, especially in Africa (Goldman 2010; van der Gaast et al. 2009). This can be partly attributed to the lack of STI capacity in developing countries. Moreover, CDM projects lacked an international STI framework that could sustain technology transfer and strengthen the capabilities of local firms to build strong and competitive global industries. As a result, the diffusion of low-carbon technology has been uneven. CDM projects have arguably been the largest market-based mechanism to facilitate low-carbon technology transfer to developing countries (Koch et al. 2014; Schneider et al. 2008). Nevertheless, the MDGs failed to emphasize the importance of the CDM projects.

As part of the 2030 Agenda, the SDGs and the recent Paris Agreement of UNFCCC aspire to transform the ways in which climate change and sustainable development issues are addressed. The Paris Agreement calls for a new STI policy framework to facilitate low-carbon technology transfer as part of the implementation of sustainable development programs. For both the Paris Agreement and the SDGs, the current absence of a broadly accepted international STI framework remains an impediment. Despite this limitation, donors including the international community and developing-country governments continue to promote the potential application of STI in addressing sustainable development challenges without a holistic approach to move the STI activities forward. A key question is how should stakeholder groups come together to prioritize investments, IPR reforms, and trade regulations that shape overall creation and deployment of STI to facilitate the implementation of the 2030 Agenda, including SDGs in developing countries.

Beyond the need for an international STI framework, the participation of a wider range of stakeholders including country governments, donors, nongovernmental organizations, academia, and the private sector is key to achieving global STI partnerships, especially where primary incentives to access innovation is driven by markets. The overall success of the SDGs will depend on various global socioinstitutional and governance factors, including the extent to which countries formalize their SDG commitments, strengthen global STI solutions and policy arrangements, and translate global SDGs into national contexts while integrating the environmental, economic, and social pillars of sustainable development.

\section{Financing SDGs Requires Global Partnership}

The pairing of SDGs with STI requires not only funding to carry out the needed research, development, and deployment to advance global goals, but also strong and coherent partnerships engaging diverse stakeholders to set priorities, evaluate plans, implement projects, and monitor the agreed upon programs at all levels. The recognition of the need for partnerships goes back to the 1992 Earth Summit in Rio and the creation of Agenda 21 which called for a global partnership that included important 
ideas such as science for sustainable development. By the time we get to the present day, recognition of the need for cooperation is so great that there is an entire SDG devoted to it, SDG17 (global partnership for sustainable development).

On the monetary side, the UN estimate is that meeting the global goals would require \$5-7 trillion annually through until 2030. Roughly half of this amount is already being spent on infrastructure and other activities, so the estimate for additional "gap" funds is \$2-3 trillion annually. To put this in perspective, annual global GDP is over $\$ 100$ trillion on a purchasing power parity (PPP) basis, suggesting that providing $\$ 2-3$ trillion could be in the realm of possibility (BSDC 2019). The three themes that we have chosen for this book, environment and energy, health, and agriculture, tend to be on the high end of expenditure given that all three engage the science to germinate ideas, the technology central to increasing productivity and well-being, and the flow of innovation needed to be able to adapt to a wide range of geographic and demographic contexts. Still, on a benefit-cost basis at the broadest level, it is reasonable to speculate that the health and welfare benefits of actually meeting the SDGs related to the three themes would greatly outweigh the costs.

Neither finance nor partnerships have been overlooked in the ambitious effort to create SDGs and move them forward. While the MDGs were more governmentcentered, the private sector has been called on many times to pave the way for creating the investment required to pursue the SDGs. The final report of the Business and Sustainable Development Commission, for example, is titled Ideas for Action for a Long-term and Sustainable Financial System (BSDC 2019). It is organized by focus areas including creating pools for long-term finance and getting infrastructure finance right. The Commission's flagship report, Better Business, Better World, describes how "sustainable business models" could attract \$12 trillion in new market value and create as many as 380 million jobs by 2030 (BSDC 2017).

Regarding partnerships, Unilever, a company that has been active and effective in integrating SDGs, created a 2018 report on How to ... Build Partnerships to Change the World, based on the idea that SDGs require important work across business, civil society, and government. A key barrier confronting many of the suggestions in this book is that the vast majority of private capital is spent in developed countries and over half of the monetary estimate for SDG implementation is required in developing countries. One inspiring crossover example is a partnership by the UK Department for International Development and Unilever that created an innovation fund ( $£ 40$ million), TRANSFORM, with the aim to enable 100 million people in subSaharan Africa and Asia to gain access to products and services related to health, livelihood, and environment or well-being (Unilever and Department for International Development 2019).

It is easy to observe that there is never enough money for STI. And failure to pay adequate attention to $\mathrm{R} \& \mathrm{D}$ investment for any of the three themes covered in this book may undermine the implementation of relevant SDGs at the national level and international levels. In chapter 3, Timilsina and Shah emphasize the need to increase R\&D investment in renewable energy technologies especially in Africa and South 
Asia, where billions of people still lack access to electricity and cooking fuels. This is reflected in another study which also emphasizes that investment in energy infrastructure is very limited in Africa as current annual spending is estimated at $\$ 8$ billion compared to an estimate of investment need of $\$ 55$ billion yearly until 2030 (Africa Progress Panel 2015). Also, in chapter 7, the authors Machado and Young analyze expenditure on R\&D for environmental science in Brazil, finding that there is a substantial shortfall in government expenditures despite many improvements in the nation's STI programs. Beyond the funding itself, the fragmented practice of grant giving and the prolonged timetables of public funding surely inhibit the achievement of many good intentions.

Imagine expanding this single study and applying it globally. This suggests what is likely the most difficult aspect of managing SDGs-the sheer level of coordination needed to make the changes that SDGs demand for a better world. We have seen that some of the work on finance and partnerships has been thoughtful and, like the SDGs themselves, even visionary. The execution, however, is demanding-requiring wisdom, patience, and forbearance that can seem distant from our competitive, sped-up world.

One distinct challenge for the SDG agenda is how to actively engage various institutions, sectors, and actors especially at the national and regional levels in order to achieve synergy for mobilizing and accessing STI finance at the international level. Yet this problem persists without a coherent approach to accessing finance for the implementation of sustainable development projects, especially in developing regions (Adenle, Ford et al. 2017). Further, despite the increased demand for the mobilization of financial resources for achieving SDGs, previous evidence suggests that lack of transparency, potential interests of various actors, unevenly distributed finance, and limited capacity at the national level remain as obstacles particularly with regard to the implementation of relevant STI projects. For example, evidence indicates that mitigation projects such as renewable energy were only funded in Africa where institutional capacity was relatively strong (Adenle, Manning et al. 2017). These challenges call for global partnerships to increase access to finance especially at the UN level, where strong leadership, higher levels of commitment, and improved allocation of responsibilities can be coordinated.

\section{The Structure of the Book}

This book examines the relationship between STI and the 2030 agenda for sustainable development, providing examples, experiences, and case studies from around the world. It uses an interdisciplinary approach to examine the contributions of STI to the implementation of the SDGs across various continents including Asia, Africa, South America, and Europe. The inclusion of contributions from multiple disciplines provides for a broad range of perspectives and ideas on how to address the challenges at which the SDGs are targeted. 
The book focuses on three human-development themes-environment and energy, health, and agriculture - as these sectors are major ones in which a STI approach can support SDG goals. The chapters highlight how STI initiatives have been applied to address each of the themes. They explore a range of STI solutions and governance arrangements. The themes are described further in the following sections.

\subsection{Theme I: Environment and Energy}

The environment and energy theme has nine chapters on SDG-related topics ranging from evaluation of biodiversity institutions at the global level to financing environmental STI at the country level (in Brazil), to the outlook on autonomous vehicles at the local, city level. There are four chapters on renewable energy, including two that are empirical and two that are relatively theoretical. All of these mention solar energy and, from an STI perspective, it is easy to see that better planning and implementation of solar energy could quickly change the status of millions of people in Africa and Asia who would achieve energy access. Altogether, the chapters unite many critical pieces that present a wider platter of possibilities for more rapid implementation of renewable energy.

Chapter 2 on biodiversity by Stevens proposes that innovation around wildlife conservation linked to SDGs is within our reach as a means of reducing biodiversity loss if we can learn from past efforts. In earlier days, a fragmented system of biodiversity governance came into being. Over time, this system has developed localized centers of innovation that would, passing on STI improvements from smaller groups to larger ones, raise the chances for acceptance and transfer of innovation across scales.

What can be learned from the four energy chapters $(3,4,5$, and 6$)$ related to STI for SDGs? Overall, SDG7 stresses "universal access to affordable, reliable and modern energy services for all” by 2030. In chapter 3, Timilsina and Shah regard such energy as a "golden thread" that is linked to numerous other SDGs and is therefore critical to achieving many SDGs simultaneously. Adenle examines solar energy and SDGs in Kenya and South Africa in chapter 4. He emphasizes not only the educational, diet, wealth, and time-management benefits that are possible with increased dissemination of solar energy, but also the importance of African government policy enabling these benefits through investment in R\&D programs and provision of appropriate subsidies. As a clean technology, solar energy has advantages over conventional sources because lower air emissions are accompanied by health and environmental benefits.

Schmidt and colleagues, in chapter 5, examine small, isolated renewable energy micro-grids that can serve a number of households independent of the main grid. The authors track these decentralized systems in three countries-Cambodia, Indonesia, and Laos-following the methodology of technological innovation systems that uses multilevel analysis to compare across these countries. They stress the importance of social and cultural differences and the need to consider each country's 
energy needs individually. Finally, Kemp and colleagues in chapter 6 explore three successful instances of the phasing in of solar energy and energy efficiency in China and India. They use an integrated framework that merges political economy elements of interests, ideas, and institutions with capabilities and policy delivery. Through this the authors find that there are positive and useful opportunities for developing countries to economize by advancing STI activities influencing several SDG targets simultaneously, given the interdependencies among them.

The theme of chapter 7, authored by Machado and Young, is whether countries provide sufficient resources for the environmental science and technology innovation that is needed to meet SDG-related goals in the detailed example of Brazil. By making reasonable and transparent assumptions about the level of financing that would be needed to fully fund $R \& D$, the study reveals a significant financial gap and an urgent need to create alternative sources of funding or to find new sources from taxes and user fees.

The SDGs are highly cross-cutting and require expertise from numerous perspectives. Addressing these needs, chapter 8 by Chertow and colleagues presents the relatively new systems science of industrial ecology and outlines how it can contribute to the delivery of SDGs. Using tools such as life-cycle assessment and material flow analysis and approaches such as industrial symbiosis, industrial ecology provides many useful takes on physical resource use and efficiency in the quest to achieve SDGs.

As presented by Wang and Oster in chapter 9, transportation for passengers and freight plays a crucial role in achieving many SDGs. The core message of their work is that the revolution anticipated by the introduction of autonomous vehicles seems unlikely to radically change ground transportation in the near future given the challenges and uncertainties associated with highly automated (“driverless") vehicles.

Understanding how systems respond to technological change, including from STI interventions targeted at SDGs, it is important for policy leaders to know in advance about the rebound effect. Vivanco and Makov in chapter 10 present the idea of rebound effects, explaining how they can reduce the level of environmental benefit that a policy delivers when inherent conflicts arise based on interacting effects. For example, when the fuel efficiency of automobiles increases, drivers may decide to travel greater distances because it is cheaper. Rebound effects are a particular risk with the SDGs because they are so interlinked.

\subsection{Theme II: Health}

Chapters in the health theme examine how health is intrinsically linked to 16 targets across the 17 SDGs. The SDG framework provides an expansive approach to creating better health systems. The health theme has seven chapters on SDG targets, emphasizing the role of new and emerging technologies in solving key health problems in both developed and developing countries. It also covers a healthcare innovation approach and entrepreneurship programs targeted at health. The issues range from STI 
approaches to responsible innovation in health such as the development of vaccines, biotherapeutics, and antimalarial treatments, digital health, urban sanitation services and infrastructure, and regulatory innovations to tackle accessibility, affordability, and safety of healthcare.

Four chapters deal with empirical examples of STI to meet SDG goals, including vaccine innovations, antimalarial drug development and diffusion, sanitation innovations in informal settlements, and the role of animal-source food in healthy diets. One chapter focuses on the supportive role of digital health in meeting SDGs, and three chapters are more methodologically oriented, focusing on health technology assessment (HTA) methods to improve the contributions of STI to SDGs, a new sustainable innovation framework for meeting SDGs, and the role of responsive and responsible science and technology studies for global health. Overall, the chapters in the health theme cover crucial aspects of scientific and technological developments aiming for SDG targets. They discuss the socioeconomic, regulatory, and institutional challenges for sustainable innovations, and novel inclusive methodologies, frameworks, and supporting digital innovations to overcome these systemic barriers.

Chapter 11 by Possas and colleagues provides insights into the technological and regulatory challenges affecting access to vaccines in developing countries and recommendations for vaccine STI performance strategies to achieve relevant SDGs. From a global sustainability perspective, only SDG3.b.1 refers explicitly to vaccines. The authors, however, identify fourteen vaccine-related goals in the SDGs, of which SDG9 (sustainable industrialization) and SDG17 (global partnership for sustainable development) are specifically related to innovation and technological development of vaccines. The authors provide recommendations for specific vaccine STI performance indicators and strategies to achieve these fourteen vaccine-related SDGs.

Readers will also learn about how development-focused HTA can help support decisions about the introduction of new technologies for the achievement of SDG3 (healthy lives). Chapter 12 by Bouttell and colleagues sketches five different scenarios regarding biopharmaceutical innovations in low- and middle-income countries. It shows how HTA can improve the efficiency of research prioritization and development processes while ensuring that the needs of vulnerable populations are met.

A novel sustainable innovation framework based on availability, affordability, accessibility, and acceptability dimensions of the SDGs has been developed in chapter 13. This framework by De Haan and Moors can be applied in low-income and middle-income countries to innovations for communicable diseases, such as malaria, tuberculosis, and HIV/AIDS. The ending of these epidemics that are mostly prevalent in low- and middle-income countries (SDG3.3) cannot be separated from universal access to healthcare (SDG3.8). The same holds for malaria burden versus poverty (SDG1), education (SDG4), and equality between countries (SDG10). Additionally, water and sanitation conditions (SDG6) and global warming (SDG13) may affect living conditions of mosquitos and therefore also affect malaria infections.

Given this interrelated, multifaceted nature of SDGs, systemic approaches should be at the root of tackling global health challenges. For example, progress toward the 
sustainable development goal on water and sanitation (SDG6) is very slow and the lack of sanitation is especially persistent in rapidly growing cities in the Global South. Chapter 16 by Van Welie and Truffer shows how such a sociotechnical systems approach helps us understand the interaction between health and sanitation technologies and services, the infrastructure and institutions which need to be in place, and the user practices of new health technology.

There is also a need for responsive and responsible innovations for global health in context, as discussed in Engel and colleagues in chapter 15. For example, in the development and implementation of point-of-care diagnostics and development of cook stoves in low- and middle-income countries, there should be continuous interrogation and reflection on the localized consequences (intended and unintended) of new innovations rather than use of traditional technology transfer mechanisms. Chapter 14 by Poon and colleagues focuses on the benefits of digital health for the achievement of SDGs. This chapter evaluates the potential relations between digital and universal health (SDG3), inclusive and equitable education (SDG4), and reduction of inequality (SDG10). More specifically, the authors show how digital health could be articulated and evaluated in four dimensions-translation, education, transformation, and technology — to bridge the gap between digital health and SDGs.

The health section ends with a holistic approach for stakeholder engagement in animal-sourced foods in sustainable, ethical, and optimal human diets, as proposed by de Bruyn and colleagues in chapter 17. An ambition of the 2030 Agenda is to include health in development, and to recognize that good health depends on and contributes to other development goals, underpinning social justice, economic growth, and environmental protection (Dye 2018). As proposed by Dye (2018), it is important to expand the scope and enhance the effectiveness of the systems and the services that prevent and treat illness to advance health and development. In this way the 2030 SDG Agenda is also an expanded agenda for systems research, assuming that better systems can indeed deliver substantially better health and well-being for all.

\subsection{Theme III: Agriculture}

Agricultural STI has made enormous contributions to development in the past, and has great potential to do so again in future. Although the global percentage of people living in rural areas has fallen below $50 \%$, it is still well over $50 \%$ in much of Asia and Africa. Particularly in these countries, agricultural issues are connected to multiple SDGs and often involve trade-offs between them. The eight chapters in this theme present a range of agriculture-related opportunities and challenges for achieving the SDGs.

Four of the chapters focus on particular technologies or sets of technologies: technologies for providing nitrogen to crops; integrated crop management for rice; crop biotechnology; and climate-smart agricultural technologies. In each case, the SDG-related issues raised range across food production (SDG2), poverty reduction 
(SDG1), environmental protection (SDG6 and SDG15), and various others. The other four chapters are more cross-cutting, covering the nexus between production, supply chains, policy, and sustainability; transformation governance that strives for economic development while protecting the livelihoods of the poor who depend on the same resources; the method of value network analysis (VNA) that assists with reorganizing businesses in ways that can contribute to multiple SDGs; and a framework for responsible scaling of agricultural innovations, so that the delivery of SDGs is maximized with limited negative consequences.

The section starts with chapter 18 by Harpankar on nitrogen management. Ensuring that crops have adequate nitrogen to yield well is important for food production (SDG2, end hunger) and the economic welfare of farmers (SDG1, end poverty). In traditional systems, nitrogen largely comes from natural sources and is applied at modest rates, but as farmers adopt modern technologies in order to increase their productivity, they apply more nitrogen and rely increasingly on artificial fertilizers. While this helps farmers with their economic goals, it can result in serious problems of water pollution (SDG6, water and sanitation for all), and it involves higher emissions of greenhouse gases (SDG13, combat climate change). Harpankar discusses a range of technologies that may help to strike a better balance between production and pollution.

We then look at crop management for poverty reduction (SDG1) and food security (SDG2) for smallholder rice producers in Timor Leste. In chapter 19, RolaRubzen and colleagues investigate integrated crop management, a comprehensive package of measures including high-yielding varieties, high-quality seed, bestpractice transplanting, and sound harvesting practices. They find that farmers who adopt these technologies have significantly higher yields and higher incomes. However, in common with some other favorable agricultural technologies, adoption across the population of farmers is disappointing. This throws the spotlight onto whether improved forms of agricultural "extension" (including information provision and training) can be devised and delivered to overcome adoption barriers.

While Rola-Rubzen mainly covers what might be termed "low-tech" solutions, Adenle and colleagues in chapter 20 discusses the potential of biotechnology to contribute to delivery of SDGs. The potential role of genetically modified organisms (GMOs) in addressing low agricultural productivity (SDG1), tackling malnutrition (SDG2), and adapting to climate change (SDG13) is considered to be very large. However, the persistent opposition to the application of GMOs in Europe and parts of developing regions (Africa, Asia, South America, Central America, and Latin America) is inhibiting the delivery of these SDGs. The authors suggest that an international GMO regulatory framework would assist in achieving acceptance of biotechnology solutions where appropriate. They also argue for use of risk-assessment models that suit local circumstances in developing countries rather than following the lead of certain developed countries that have chosen a highly conservative precautionary approach. 
With an emphasis on climate change (SDG13), but with consequences for various other SDGs, Mwongera and colleagues explore the potential for "climatesmart agriculture" (CSA) in Africa (chapter 21). CSA encompasses measures for both adaptation to and mitigation of climate change, including minimum tillage, improved crop varieties, and integrated pest management. Mwongera presents a novel process for rapid appraisal of CSA, and applies it to case studies in Tanzania, Kenya, and Uganda. As with integrated crop management in Timor Leste, adoption of CSA in these three African case studies is found to improve farmers' incomes (SDG1), with some elements of the package being more beneficial than others.

In chapter 22, Flocco unpacks the soybean "production complex" in Brazil, with the aim of identifying levers that can help to deliver SDGs. She argues for a systems approach, including actions along the supply chain, from the adoption of best management practices in agricultural fields to development of supportive governance frameworks at the policy level. The approach is essentially market-based, but with an emphasis on conserving soils, with consequences for poverty (SDG1), hunger (SDG2), health (SDG3), water quality (SDG6), and others.

Another high-level perspective on SDGs in a primary industry is provided by Wedig (chapter 23), who presents the concept of "transformation governance" in the context of small-scale fishers in Lake Victoria, which contains Africa's largest inland small-scale fisheries sector, involving over three million people. Challenges are created by a growing commercial aquaculture industry operating in the lake, with risks to social and environmental sustainability. Wedig's three-part approach to governance is designed to manage these risks.

A different way of analyzing agricultural industries is provided by VNA, as explained by Dentoni and colleagues in chapter 24. They describe how VNA can be used as a diagnostic tool for actors seeking to reduce poverty (SDG1) and hunger (SDG2), enhance economic growth (SDG8), and other SDGs. Their case study of the Agricultural Commodity Exchange in Malawi reveals a number of options for building cross-sector partnerships that can utilize STI to help deliver SDGs.

Finally, we address the crucial issue of delivering SDGs at scale. Wigboldus and colleagues (chapter 25) identify the need for a "theory of scaling" to help make sure that efforts to deliver SDGs are successful at large scales rather than just locally. They highlight that the process of scaling up to large impact is often more complex than accounted for by policymakers and program managers. In unpacking what is inside the black box of unarticulated assumptions about scaling, they identify a broad range of relevant issues, including that scaling often involves multiple linked steps, the importance of understanding the characteristics of the innovation being scaled and how these characteristics fit with the needs of potential users, that scaling always involves a range of partners and stakeholders, and the need to link the theory of scaling to decision-making processes. This chapter has relevance to all of the SDGs, each of which needs to be delivered at large scale. 


\section{Conclusion}

Readers of this book will come away with no doubt that STI can be a powerful tool for delivery of SDGs. Indeed, delivery of some SDG targets is likely to be impossible without major contributions from STI. However, readers will also come to appreciate that harnessing and applying STI effectively in the pursuit of development goals is often not straightforward.

The chapters of this book help to identify the challenges and complexities that must be grappled with in order to succeed in the delivery of SDGs through STI. The challenges and complexities described and analyzed are many and varied, ranging from the need to account for trade-offs between different SDGs when particular technologies or innovations are being considered for application, to the risk of unexpected consequences from application of technologies or innovations, to the existence of community opposition to certain types of science or certain technologies, removing them from the available toolkit via the political process, to the need for supportive policy environments, capable institutions, and good governance if STI is to deliver on its potential. These and many other issues are expanded on throughout the book. The book as a whole provides a wealth of analysis, experience, insights, and cautions that will be valuable to all who are involved in efforts to utilize STI in the delivery of SDGs.

\section{References}

Adenle, A. A., Azadi, H., and Arbiol, J. (2015). Global assessment of technological innovation for climate change adaptation and mitigation in developing world. Journal of Environmental Management 161, 261-275.

Adenle, A. A., Ford, J. D., Morton, J., Twomlow, S., Alverson, K., Cattaneo, A., Cervigni, R., Kurukulasuriya, P., Huq, S., Helfgott, A., and Ebinger, J. O. (2017). Managing climate change risks in Africa-a global perspective. Ecological Economics 141, 190-201.

Adenle, A. A., Manning, D. T., and Arbiol, J. (2017). Mitigating climate change in Africa: barriers to financing low-carbon development. World Development 100, 123-132.

Africa Progress Panel (2015). Africa Progress Report 2015. Africa Progress Panel. https://reliefweb.int/report/world/africa-progress-report-2015-power-people-planet-seizing-africasenergy-and-climate (accessed April 5, 2019).

Biermann, F., Kanie, N., and Kim, R. E. (2017). Global governance by goal-setting: the novel approach of the UN Sustainable Development Goals. Current Opinion in Environmental Sustainability 26-27, 26-31.

Bozeman, B. (2000). Technology transfer and public policy: a review of research and theory, Research Policy 29(4), 627-655.

Business and Sustainable Development Commission (BSDC) (2017). New paper. How the world can finance the SDGs. http://businesscommission.org/our-work/new-report-howthe-world-can-finance-the-sdgs (accessed April 8, 2019).

Business and Sustainable Development Commission (BSDC) (2019). Better Business, Better World. BSDC, London. http://report.businesscommission.org/uploads/BetterBizBetterWorld_170215_012417.pdf (accessed April 8, 2019). 
Chung, S. (2002). Building a national innovation system through regional innovation systems. Technovation 22(8), 485-491.

Dechezleprêtre, A., Glachant, M., and Ménière, Y. (2009). Technology transfer by CDM projects: a comparison of Brazil, China, India and Mexico. Energy Policy 37(2), 703-711.

Dye, C. (2018). Expanded health systems for sustainable development. Science 359(6382), 1337.

Global Sustainable Development Report (GSDR 2016). Perspective of Scientists on Technology and SDGs, Chapter 3, United Nations. https://sustainabledevelopment.un.org/content/documents/10789Chapter3_GSDR2016.pdf (accessed April 5, 2019).

Goldman, M. (2010). Kuyasa CDM project: renewable energy efficient technology for the poor. United Nations Development Programme (UNDP) http://www.growinginclusivemarkets. org/media/cases/SouthAfrica_Kuyasa_2010.pdf (accessed April 5, 2019).

Holdren, J. P. (2008). Science and technology for sustainable well-being. Science 319(5862), 424-434.

Kanie, N., Bernstein, S., Biermann, F., and Haas, P. M. (2017). Introduction: Global governance through goal setting. In: Kanie, N., and Biermann, F. (Eds.), Governing Through Goals: Sustainable Development Goals as Governance Innovation, pp. 1-28. MIT Press, Cambridge, Massachusetts and London, England.

Khan, R. (2016). How frugal innovation promotes social sustainability. Sustainability 8, 1034.

Knack, S., and Keefer, P. (1995). Institutions and economic performance: cross-country tests using alternative institutional measures. Economics and Politics 7(3), 207-227.

Koch, N., Fuss, S., Grosjean, G., and Edenhofer, O. (2014). Causes of the EU ETS price drop: Recession, CDM, renewable policies or a bit of everything?-new evidence. Energy Policy 73, 676-685.

Levänen, J., Hossain, M., Lyytinen, T., Hyvarinen, A., Numminen, S., and Halme, M. (2016). Implications of frugal innovations on sustainable development: evaluating water and energy innovations. Sustainability $8,4$.

Roffe, P., and Santa Cruz, M. (2007). Intellectual property rights and sustainable development: a survey of major issues. Economic Commission for Latin America and the Caribbean (ECLAC). Sustainable Development and Human Settlements Division, the project ROA/49.

Schneider, M., Holzer, A., and Hoffmann V. H. (2008). Understanding the CDM's contribution to technology transfer. Energy Policy 36(8), 2930-2938.

Seyfang, G., and Smith, A. (2007). Grassroots innovations for sustainable development: Towards a new research and policy agenda. Environmental Politics 16(4), 584-603.

Unilever and Department for International Development (2019). Welcome to TRANSFORM. https://www.transform.global (accessed April 8, 2019).

United Nations (UN) (2002). Implementation of the United Nations Millennium Declaration, Report of the Secretary-General. United Nations General Assembly, New York.

United Nations (UN) (2014). Science, technology and innovation for the post-2015 development agenda. Economic and Social Council. Report of the Secretary-General. Seventeenth session, Geneva, May 12-16.

United Nations (UN) (2015). Transforming Our World: the 2030 Agenda for Sustainable Development, A/RES/70/1. United Nations, New York.

United Nations (UN) (2016). Science, technology, innovation and capacity-building: Chapter II.G. Addis Ababa Action Agenda-Monitoring commitments and actions. http://www. un.org/esa/ffd/wp-content/uploads/2016/03/2016-IATF-Chapter2G.pdf (accessed April $5,2019)$.

United Nations (UN) (n.d.). Technology facilitation mechanism. https://sustainabledevelopment.un.org/tfm (accessed April 6, 2019).

United Nations Conference on Trade and Development (UNCTAD 2017). New innovation approaches to support the implementation of sustainable development goals. https:// unctad.org/en/PublicationsLibrary/dtlstict2017d4_en.pdf (accessed April 5, 2019). 
United Nations Economic and Social Council (2004). Promoting the application of science and technology to meet the Development Goals contained in the Millennium Declaration. Report by the Secretary-General, Commission on Science and Technology for Development, Seventh session, Geneva, May 24-28, 2004, Item 2 of the provisional agenda. https://unctad. org/en/Docs/ecn162004d2_en.pdf (accessed April 8, 2019).

van der Gaast, W., Begg, K., and Flamos, A. (2009). Promoting sustainable energy technology transfers to developing countries through the CDM. Applied Energy 86(2), 230-236.

World Bank (2010). Innovation Policy: A Guide for Developing Countries. World Bank, Washington, DC.

World Bank (2018). Poverty. https://www.worldbank.org/en/topic/poverty/overview (accessed April 5, 2019). 